\title{
THE USE OF SILVER SULPHADIAZINE OCCLUSIVE DRESSINGS FOR FINGER-TIP INJURIES
}

\author{
P. de BOER, P. O. COLLINSON \\ From The Department of Orthopaedic Surgery, St Thomas' Hospital, London
}

\begin{abstract}
A prospective trial was performed, comparing the use of silver sulphadiazine occlusive dressings with Fucidin gauze compressive dressings in the treatment of injuries to the finger-tip in patients presenting at the casualty department. Sixty-four patients were seen, four of whom had severe injury with extensive loss of pulp. The time taken for the wound to heal, the incidence of infection, and the duration of absence from work were compared for both types of treatment. The results showed that silver sulphadiazine occlusive dressings were the most effective in the treatment of these injuries even when they were severe.
\end{abstract}

Injuries of the finger-tip are extremely common. Up to 100000 patients a year are seen in British accident and emergency departments (Clarkson 1961). There is no doubt that finger-tips which are cleanly cut off can be treated very well by plastic procedures such as Kutler's repair (Kutler 1947), or the central pad V-Y advancement flap (Atasoy et al. 1970). However, these procedures require considerable surgical expertise, which is not commonly found in accident and emergency departments 24 hours a day. The majority of such injuries seen at St Thomas' Hospital are caused by blunt trauma: they are often heavily contaminated, and are not suitable for plastic operations.

Holm and Zachariae (1974) have pointed out that, where neither a primary suture nor a plastic procedure is possible, the best end-results can be achieved by conservative treatment. This consisted of applying Fucidin gauze and compressive dressings, which were changed every five days. The disadvantages of this method include the risk of sepsis, and the fact that the patient is often unable to return to work while the dressings are still in place. Consequently, we investigated a different method of treatment between January and August 1980 when we compared the results for injuries to the finger-tips treated in two different ways. Half were treated with Fucidin gauze and compressive dressings; the other half had silver sulphadiazine (Flamazine) occlusive dressings applied.

Silver sulphadiazine cream has been used in the treatment of burns for many years (Fox 1968; Fox, Rappole and Stanford 1969). This method had been remarkably successful with burnt hands in particular. The raw surfaces are simply covered with the cream, and a non-sterile rubber glove is applied (Reid 1974). This not only reduces the incidence of infection, but also allows very early active and passive movements of the joints.

\section{MATERIALS AND METHODS}

Between January and August 1980, 64 patients with injuries to the finger-tips were seen in the $A$ and $E$ department at St Thomas' Hospital. All patients were given local anaesthesia (ring block). and the wound was thoroughly cleaned. Four patients, who had very severe injuries, were considered separately. The remaining 60 patients were treated either with Fucidin gauze or silver sulphadiazine cream; alternate patients were allocated to each treatment.

Silver sulphadiazine cream was applied to the cleaned wounds (Fig. 1). The finger portion of an ordinary, non-sterile, surgical glove was cut off to produce a finger stall. which was then put on the finger. The completed dressing was held in place with micropore tape (Fig. 2).

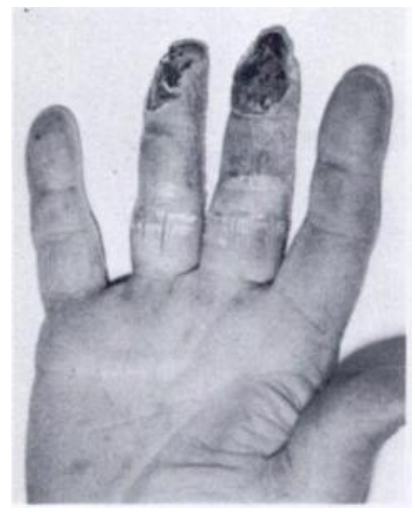

Fig. 1

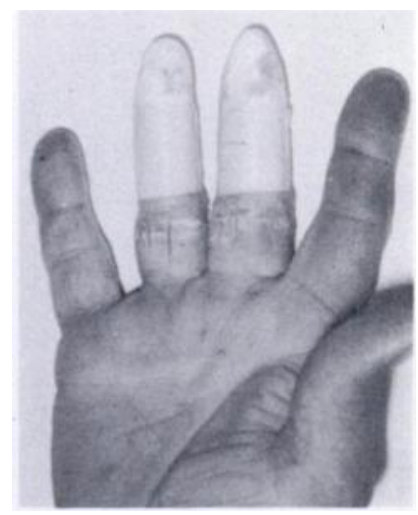

Fig. 2
Figure 1 -The dominant hand of a manual labourer was crushed in a lift-door with injury to the ring and middle fingers. The wounds were cleaned before application of silver sulphadiazine occlusive dressings. Figure 2-The application of silver sulphadiazine occlusive dressing to the hand shown in Figure 1. Note the use of a non-sterile glove.

P. de Boer, MB, BChir, FRCS, Orthopaedic Registrar, Bronx Municipal Hospital Centre, Pelham Parkway, South and East Chester Road, Bronx, New York 10461, USA.

P. O. Collinson, BA, BChir, House Surgeon, c/o Doctor's Mess, St Peter’s Hospital, Guildford Road, Chertsey, Surrey KT16 ()PZ. England. Requests for reprints should be sent to $\mathrm{Dr} \mathrm{P}$. O. Collinson.

(1) 1981 British Editorial Society of Bone and Joint Surgery 0301-620X/81/4117-0545 $\$ 2.00$ 
When silver sulphadiazine cream is used, a considerable amount of fluid collects underneath the occlusive portion of the dressing. After about 48 hours, this usually leaks through any adhesive dressings and patients should be warned that this may occur. Our policy is to put a gauze dressing over the rubber glove to absorb any such leakage during the first week of treatment. Tetanus prophylaxis was given in all cases, but no systemic antibiotics. All patients were followed-up until the wound healed and were urged to report if they had further problems.

\section{RESULTS}

Sixty patients were involved in the trial, four of whom each had two fingers injured. Results are expressed in terms of the number of patients injured (Tables I and II). Complications. Four children were among the patients treated with silver sulphadiazine occlusive dressings; in all four the dressing fell off. This was due to a combination of poor adhesiveness at the base of the dressing combined with vigorous activities undertaken by the child. Although none of these children developed secondary infection, and all of their wounds healed, the method cannot be recommended for children. One patient was hypersensitive to the rubber of the glove; the dressing was reapplied using a latex glove which did not produce any skin reaction.

Severe injuries. Four patients were seen in whom there was extensive loss of the pulp space, together with loss of part of the terminal phalanx. All these injuries were caused by crushing and involved the tip of the finger which was sliced obliquely. Formerly it was our policy to

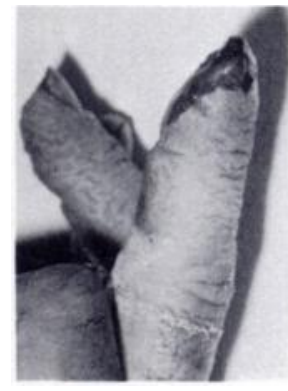

Fig. 3

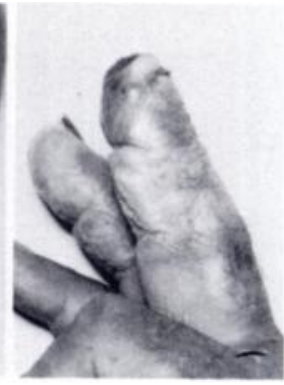

Fig. 4

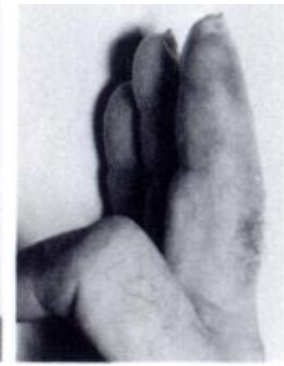

Fig. 5
Figure 3-The lateral view of the hand one day after application of the silver sulphadiazine occlusive dressing. Note the oblique angle of injury and extensive loss of pulp. Figure $4-$ The lateral view of the third finger of the hand of the same patient 14 days after application of the silver sulphadiazine occlusive dressing. Figure 5-The lateral view of the hand of the same patient eight weeks from the time of the original injury. A protective sensation is present in the finger-tip. Note that remodelling of the pulp has occurred.

\section{DISCUSSION}

Occlusive silver sulphadiazine dressings clearly reduce the time needed for healing in uncomplicated injuries of the finger. The reduction from 17.6 to 12.2 days is statistically significant $(P=0.05)$. The treatment permits patients to return to work earlier than they would with other forms of treatment. No patient treated with silver sulphadiazine developed sepsis. This contrasts with four cases of sepsis in the group treated with Fucidin gauze. Those four patients took a very long time to heal and three were away from work for a considerable time. If

Table I. Comparison of the healing times for 60 patients in the two treatment groups

\begin{tabular}{|l|c|c|c|c|c|}
\hline \multicolumn{1}{|c|}{ Treatment } & $\begin{array}{c}\text { Number of } \\
\text { patients }\end{array}$ & $\begin{array}{c}\text { Mean area } \\
\text { of skin loss } \\
\left(\mathbf{m m}^{2}\right)\end{array}$ & $\begin{array}{c}\text { Mean number } \\
\text { of visits } \\
\text { to hospital }\end{array}$ & $\begin{array}{c}\text { Days needed } \\
\text { for healing } \\
(\text { mean } \pm \text { SE) }\end{array}$ & $\begin{array}{c}\text { Number } \\
\text { infected }\end{array}$ \\
\hline Fucidin gauze & 31 & $\begin{array}{c}60 \\
(25-150)\end{array}$ & $\begin{array}{c}4 \\
(2-11)\end{array}$ & $\begin{array}{c}17.6 \pm 4.3 \\
(5-60)\end{array}$ & 4 \\
Silver sulphadiazine cream & 29 & $\begin{array}{c}50 \\
(25-150)\end{array}$ & $\begin{array}{c}3.4 \\
(2-5)\end{array}$ & $(2-32)$ & 0 \\
\hline
\end{tabular}

Table II. Comparison of the time taken off work for patients in the two treatment groups

\begin{tabular}{|l|c|c|c|}
\hline \multicolumn{1}{|c|}{ Treatment } & $\begin{array}{c}\text { Number taking } \\
\text { time of work }\end{array}$ & $\begin{array}{c}\text { Mean number } \\
\text { of days of } \\
\text { work ( } \mathbf{( S E )}\end{array}$ & $\begin{array}{c}\text { Number } \\
\text { infected }\end{array}$ \\
\hline Fucidin gauze & 19 & $\begin{array}{c}13.8 \pm 5.9 \\
(0-42)\end{array}$ & 3 \\
$\begin{array}{l}\text { Silver sulphadiazine } \\
\text { cream }\end{array}$ & 19 & $\begin{array}{c}5.8 \pm 3.1 \\
(0-17)\end{array}$ & 0 \\
\hline
\end{tabular}

recommend primary amputation of the finger-tip for this type of injury. However, we decided to treat only one of these patients by primary amputation and to treat the other three with silver sulphadiazine occlusive dressings instead; the results were surprisingly good (Figs 3 to 5). these three are omitted from the Fucidin group, the time required for healing becomes almost identical with that for the silver sulphadiazine group: Fucidin group 15.0 days, silver sulphadiazine 12.2 days (this difference is not statistically significant). However, even when these four patients are removed from the group treated with Fucidin gauze, the time away from work remains significantly shorter in the silver sulphadiazine group: Fucidin gauze 10.8 days, silver sulphadiazine 5.8 days, $P=0.1$.

Patients with occlusive dressings may return to work which involves exposure to water or dirt. If they wear leather finger stalls over a conventional dressing the underlying dressing becomes soggy and the skin mascerated with an increased risk of infection. This does not occur when a leather finger stall is applied over an 
occlusive dressing. The only patients who were unable to return to work with a silver sulphadiazine dressing protected by a finger stall were those employed in the catering trade where they are not allowed to work with any form of dressing on their hands. The two groups had identical sex ratios. The percentage of manual labourers in the two groups was also identical and the ratio of dominant to non-dominant hand injuries was similar, as was the actual finger involved. The improvement can therefore be mainly attributed to the occlusive silver sulphadiazine dressings which permit safe, rapid healing and an early return to work.

We were especially interested in the more severe injuries. From our experience silver sulphadiazine treatment is also applicable to these rather more serious injuries involving significant loss of the pulp and terminal phalanx. We have been impressed by the remodelling of the pulp which occurs (Figs 3 to 5).

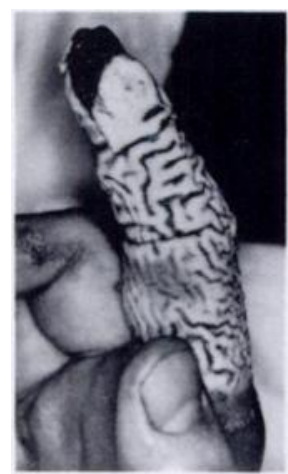

Fig. 6

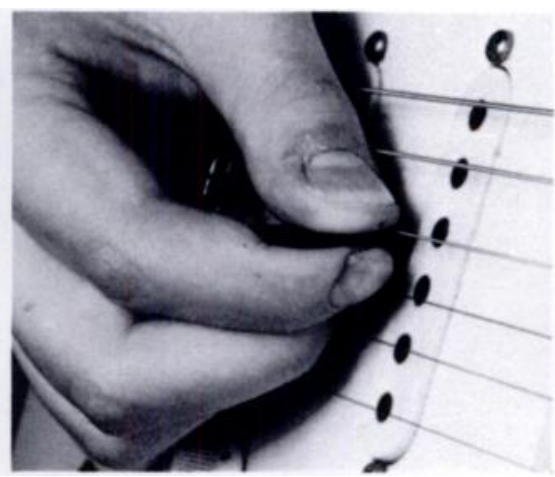

Fig. 7

Figure 6-Injury to the index finger of the dominant hand one day after application of the silver sulphadiazine occlusive dressing. Figure 7-The same patient 10 weeks from the time of the original injury. There is complete functional recovery.

Although these remodelled finger-tips are initially hypersensitive, they still function well (Figs 6 and 7).

\section{REFERENCES}

Atasoy E, Ioakimidis E, Kasdon ML, Kutz JE, Kleinert HE. Reconstruction of the amputated fingertip with a triangular volar flap. J Bone Joint Surg $[A m] 1970 ; 52-A: 921-6$.

Clarkson P. Finger-tip injuries. Br Med J 1961 ;ii: 1082.

Fox CL Jr. Silver sulfadiazine-a new topical therapy for Pseudomonas in burns. Arch Surg 1968:96:184-8.

Fox CL Jr, Rappole BW, Stanford W. Control of Pseudomonas infection in burns by silver sulfadiazine. Surg Gyn Obstet 1969;128:1021-6. Holm A, Zachariae L. Fingertip lesions: an evaluation of conservative treatment versus free skin grafting. Acta Orthop Scand 1974;45:382-92.

Kutler W. A new method for fingertip amputation. JAMA 1947:133:29-30.

Reid WH. Care of the burned hand. Hand 1974;6:163-5. 